\title{
DA CONCESSÃO DA ISENÇÃO DE IPVA, PARA PESSOAS COM DEFICIÊNCIAS, NOS CASOS DE TERCEIRO DIRIGIR VEÍCULO AUTOMOTOR, EM NOME DA SEGURANÇA JURÍDICA
}

\author{
Nayara Maria Silvério da Costa Dallefi
}

Universidade do Oeste Paulista - UNOESTE, curso de Direito, Presidente Prudente, SP.

\section{RESUMO}

O presente artigo visa tratar do princípio da segurança jurídica e sua efetividade diante a concessão da isenção do imposto IPVA nos casos em que é necessário terceiro dirigir, para o deficiente proprietário de veículo automotor, e que diante sua deficiência, é impossibilitado de conduzir o automóvel. Isto porque, diante a análise de jurisprudência, verifica-se mandados de segurança, para o fim de concessão de IPVA, para pessoas com deficiências, que receberam a isenção do IPI e ICMS na compra do veículo automotor, mas teve o indeferimento do imposto em questão, sob o argumento de não ser condutor do veículo. A partir de uma pesquisa bibliográfica, pretende concluir que indeferimentos nesta hipótese vão contra o princípio da segurança jurídica, até mesmo porque, o impetrar Mandado de Segurança, em sua grande maioria as decisões são no sentido de conceder a isenção também a estes casos.

Palavras - Chaves: Princípio da Segurança Jurídica. IPVA. Deficiente Físico.

\section{OF THE CONCESSION OF THE IPVA EXEMPTION IN THE CASES OF THIRD MOTOR VEHICLE IN THE NAME OF THE LEGAL SAFETY}

\begin{abstract}
This article aims to deal with the principle of legal certainty and its effectiveness in granting exemption from the IPVA tax in cases where it is necessary to third-party driving for the deficient owner of a motor vehicle, and that, due to his disability, he is unable to drive The automobile. This is because, due to the analysis of jurisprudence, there are mandates of security, for the purpose of granting IPVA, for persons with disabilities, who received the exemption of IPI and ICMS in the purchase of the motor vehicle, but was denied the tax in Question, on the grounds that he is not the driver of the vehicle. Based on a bibliographical research, it intends to conclude that rejections in this hypothesis go against the principle of legal certainty, even because, the writ of writ of mandamus, in the great majority the decisions are in the sense of granting the exemption also to these cases.
\end{abstract}

Keywords: Principle of Legal Security. IPVA. Handicapped.

\section{INTRODUÇÃO}

A presença do princípio da segurança jurídica em nosso direito é de forma explícita, a começar pelo preâmbulo da Constituição Federal de 1988, em que pese não tem força normativa, verifica-se a importância do referido princípio. Sem contar, que sua existência também é presente no Direito Ocidental, refletido em outros Estados, com ênfase após 1948, diante o teor da Declaração Universal de Direitos Humanos.

Corroborando com o assunto, falar das pessoas com deficiências físicas, é um assunto que deve ser colocado em pauta de muitas discussões acadêmicas, pois mesmo diante a Convenção de Nova York, que tem para nós status de Emenda Constitucional e diversos outros ordenamentos 
protetivos, verifica-se muitas vezes dificuldades para a concretização de seus direitos, assim como a concretização do princípio da isonomia jurídica, até mesmo por parte de órgãos Estatais, levando a busca do Judiciário para a concretização.

No presente trabalho, o que se visa, é tratar não só do deficiente físico, mas das hipóteses em que diante um deficiência cumulada com a impossibilidade de dirigir veículo automotor, mesmo diante a isenção do IPI e ICMS, na aquisição, tem indeferido o pedido de isenção do IPVA, sob a justificativa de que é terceiro quem irá conduzir o veículo que está em seu nome.

A indignação maior, é que muitas vezes essa pessoa com deficiência, necessita de seu veículo para realizar seu tratamento, e diante sua impossibilidade - por exemplo, deficiência visual ou menor deficiente, sendo necessário que terceiro dirija em seu lugar - tem seu pedido negado, valendo-se de interposição de Mandado de Segurança para fazer jus não a um benefício, e sim um direito, que deve ser analisado em consonância não só com o princípio da isonomia, mas também com o princípio da segurança jurídica.

Desta feita, a partir de uma pesquisa bibliográfica, com método histórico-dedutivo, será verificada algumas decisões judiciais que são positivas sobre este tema, no sentido de conceder a isenção de IPVA, efetivando a segurança jurídica e a dignidade da pessoa humana.

\section{DO PRINCÍPIO DA SEGURANÇA JURÍDICA}

Discorrer sobre segurança jurídica, é uma árdua tarefa para o operador do Direito, diante a complexidade e subjetividade do assunto, até mesmo porque a busca da efetividade do referido princípio é presente nos Estados Ocidentais, podendo ser relacionado ainda com a ideologia jurídica e política. Necessário dizer que o presente artigo, não irá discorrer sobre ideologia política - ex: nazista, comunista, fascista, democrática, etc - muito menos sobre ideologia jurídica - Carta Magna, no sentido de novo Contrato Social.

Nessa toada, a segurança jurídica que enfatiza-se aqui está voltada com as reiteradas decisões em defesa das pessoas com deficiências que buscam o Poder Judiciário, por intermédio do Mandado de Segurança, para garantir a isenção do Imposto de Propriedade de Veículo Automotor, que foi indeferido, pois embora proprietário do veículo, será terceiro quem irá conduzir.

Para Theodoro Junior (2008, p.262) “[...] o mundo do Direito, portanto, não é da Justiça (em seu feitio absoluto). É o da segurança. Sem justiça alguma o Direito - é verdade - encontrará dificuldades para manter seu projeto de pacificação social. Sem segurança, porém, o Direito simplesmente não existe".

Neste diapasão a consagração do princípio da segurança jurídica advém desde o preambulo da Carta Magna de 1988 - reforçando que não tem força normativa nesta hipótese ${ }^{1}$ - da Carta

\footnotetext{
${ }^{1}$ Consta do voto do Ministro Cesar Velloso, relator da ADI 2076-5 AC: “[...] O preâmbulo, segundo Jorge Miranda, 'proclamação mais ou menos solene, mais ou menos significante, anteposta ao articulado constitucional não é componente necessário de qualquer Constituição, mas tão somente um elemento natural de Constituiçóes feitas em momentos de ruptura histórica ou de grande transformação político social'. (Jorge Miranda, 'Estudos sobre a Constituição', p. 17). Teria o preâmbulo relevância jurídica? Jorge Miranda registra três posições da doutrina a respeito do tema: 'a tese da irrelevância jurídica; a tese da plena eficácia, colocando o preâmbulo em pé de igualdade com quaisquer disposições constitucionais; entre as duas, a tese da relevância jurídica indireta, não confundindo preâmbulo com preceitos normativos'. E o Ministro relator, após citar as lições de outros doutrinadores, pontua que '[...] O preâmbulo, ressai das lições transcritas, não se situa no âmbito do direito, mas no domínio da política, refletindo posição ideológica do constituinte. É claro que uma constituição que consagra princípios democráticos, liberais, não poderia conter preambulo que proclamasse princípios diversos. Não contém o preâmbulo, portanto, relevância jurídica. (grifei) O preâmbulo não constitui norma central da Constituição, de reprodução obrigatória na Constituição do Estado-membro. O que acontece é que o preâmbulo contém, de regra, a proclamação ou exortação no sentido dos princípios inscritos na Carta: princípio do Estado Democrático de Direito; princípio republicano, princípio dos direitos e garantias, etc. Esses princípios, sim, inscritos na Constituição, Colloquium Socialis, Presidente Prudente, v. 01, n. Especial 2, Jul/Dez, 2017, p.263-268. DOI: 10.5747/cs.2017.v01.nesp2.s0146
} 
Magna de 1988, estando presente no decorrer da Constituição Federal e em diversos ramos do direito, seja do Tributário, Difusos e Coletivos, Previdenciário etc.

Corroborando com o conceito do princípio, Ávila (2011, p.64), discorre "um elemento objetivo do ordenamento jurídico [...] um meio de garantir a dignidade da pessoa humana" 2 .

Daí a importância de relacionar a efetividade da concessão de referido imposto nos casos voltados ao tema proposto, para o fim de concretizar a segurança jurídica e em um futuro próspero, ter referido assunto consolidado pela jurisprudência e quem sabe modificar os indeferimentos por parte da administração pública nestas hipóteses.

\section{DEFICIÊNCIA E ALGUMAS FUNDAMENTAÇÕES LEGAIS}

Desde a História Antiga, verifica-se relatos e desrespeito com as pessoas com deficiências seja física ou mental, sendo que na Roma Antiga havia o absurdo de autorizar sacríficos das pessoas nessas condições - sendo que atualmente, embora não existindo as atrocidades que ocorreram no passado, ainda existe grande desrespeito ao princípio da dignidade da pessoa humana, em determinados casos. ${ }^{3}$

Após o Cristianismo, tem-se uma branda conscientização, mas nada no sentido do que temos hoje, no sentido de proteção. Isto porque algumas doenças durante a Idade Média era considerada como verdadeira maldição divina ${ }^{4}$.

Somente com a Declaração Universal dos Direitos do Homem, após a segunda guerra mundial, é verificada uma maior presença protecionista do ordenamento mundial, sobre a questão das pessoas com deficiências.

Atualmente, em nosso direito pátrio, em virtude da Emenda Constitucional $\mathrm{n} 045$, que trouxe em seu artigo 50 §3으 da CF/88, a possibilidade de tratados de Direitos Humanos, ter força de Emenda Constitucional, desde que passado pelos requisitos lá descritos, temos a Convenção de Nova York, de 30 de março de 2007, incorporada de acordo com a nova regra, conforme decreto no 6.949/2009, que trata dos Direitos das Pessoas com Deficiências, possuindo força de Emenda Constitucional.

Sem contar, do princípio da isonomia - tratar os iguais de forma igual e os desiguais de forma desigual, na medida de suas desigualdades - e tantos outros princípios e conceitos, no sentido protecionista.

Ainda, importante discorrer sobre a CORDE - Coordenadoria Nacional para Integração da Pessoa Portadora de Deficiência, Lei 7.853/89 e Decreto Federal 1.680/95, que em seu bojo discorre sobre o conceito das pessoas portadoras de deficiências.

Nessa toada, há inúmeros ordenamentos com a proteção ao Deficiente a partir do Estatuto da Pessoa com Deficiência, assim como o Direito Previdenciário, ao se preocupar na concessão de benefícios para a pessoa com deficiência, inclusive a Aposentadoria para a Pessoa com Deficiência, a Aposentadoria por Invalidez, o benefício de Prestação Continuada - LOAS ou Amparo Social, e tantos outros.

constituem normas contrais (SIC) de reprodução obrigatória, ou que não pode a Constituição do Estado-membro dispor de forma contrária, dado que, reproduzidos, ou não, na Constituição estadual, incidirão na ordem local". (BRASIL. STF, 2002).

${ }^{2}$ Ávila (2011, p.64) afirma que "A segurança jurídica também é um elemento objetivo do ordenamento jurídico. Ela é um meio de atingir o bem de todos. Quando há um elevado grau de insegurança, o indivíduo evita ações que estimulam a integração. Com isso, a cooperação social é reprimida. A segurança jurídica é, igualmente, um meio de garantir a dignidade da pessoa humana".

3 SILVA, Otto Marques da. A História da Pessoa Deficiente no Mundo de Ontem e de Hoje. Epopéia Ignorada , 1987.p.18.

${ }^{4}$ Idem. p.169.

Colloquium Socialis, Presidente Prudente, v. 01, n. Especial 2, Jul/Dez, 2017, p.263-268. DOI: 10.5747/cs.2017.v01.nesp2.s0146 


\section{DA CONCESSÃO DA ISENÇÃO DE IPVA, PARA PESSOAS COM DEFICIÊNCIAS, NOS CASOS DE TERCEIRO DIRIGIR VEÍCULO AUTOMOTOR, EM NOME DA SEGURANÇA JURÍDICA.}

A Constituição Federal de 1988, visando a real integração social de todos, dentro dos limites impostos individualmente, dedicou especial atenção aos direitos sociais como, por exemplo, no artigo 10 e $5^{\mathbf{5}^{5}}$. O legislador se preocupou em promover a integração social de todos os cidadãos, evitando, assim, toda e qualquer forma de discriminação, em garantia do direito à igualdade, principalmente entre os desiguais.

Porém, mesmo ciente de que é obrigado a promover a integração social de todos os setores desfavorecidos, de acordo com o art. 23, X, da CF, e mesmo assim, o Estado, acabava até este ano fundamentando o indeferimento na literalidade da lei $n$ o 13.296/08, art. 13, III, que diz que o condutor deve dirigir o veículo para ter isenção do IPVA.

Avança o ordenamento jurídico, na modificação do ordenamento jurídico acima, por intermédio da lei nำ13296, em que o mesmo artigo e inciso é modicado, para a seguinte redação: "III - de um único veículo, de propriedade de pessoa com deficiência física, visual, mental severa ou profunda, ou autista; (NR)". Até mesmo porque conforme será analisado na decisão abaixo, é essa a interpretação dada pelo judiciário do Estado de São Paulo, para esses casos.

Entretanto, sabemos que são muitas patologias, embora não considerada de forma expressa como deficiência física, acaba debilitando o requerente que pleiteia a isenção, como no caso de fibromialgia, podendo gerar insegurança jurídica não trazer no texto legal qual deficiência física considera passível de isenção.

Desta feita, será necessário que o veículo seja dirigido por terceiro, mas com a pessoa deficiente do lado, pois necessita de auxílio para se locomover, com evidente dependência de seus familiares, merecendo uma ampliação do texto legal para discorrer se são toda e qualquer deficiência ou de forma específica. Lembrando ainda, que para autorização da isenção de IPI e ICMS, esse argumento não é utilizado, realizando o deferimento.

Respeitando o princípio da isonomia, tem-se a jurisprudência tendenciosa a ser dominante, conforme o exemplo abaixo:

Processo no 1010406-19.2016.8.26.0482. 3a Câmara de Direito Público. Tribunal de Justiça de São Paulo. Ementa: REEXAME NECESSÁRIO MANDADO DE SEGURANÇA - ISENÇÃODE IPVA- DEFICIENTE - Pretensão de pessoa com deficiência de obter isenção de IPVA em veículo de sua propriedade - Sentença de concessão da segurança - Pleito de reforma da sentença - Não cabimento - Aquisição de veículo automotor destinado ao transporte do deficiente, portador de "síndrome de down" - Veículo adquirido em nome do deficiente, mas que será conduzido por terceira pessoa - Lei Estadual no 13.296, de 23/12/2.008 (artigo 13, inciso III), que trata da isenção do IPVA, conferindo o benefício tributário ao veículo adequado para ser conduzido por pessoa com deficiência física - Benefício fiscal que visa a inclusão social dos portadores de necessidades especiais Isenção tributária que deve ser estendida àqueles que não detêm a

\footnotetext{
${ }^{5}$ Art. 1․ A República Federativa do Brasil, formada pela união indissolúvel dos Estados e Municípios e do Distrito Federal, constitui-se em Estado Democrático de Direito e tem como fundamentos: (...) III - a dignidade da pessoa humana. Art. 3ㅇ. Constituem objetivos fundamentais da República Federativa do Brasil: (...) III - erradicar a pobreza e a marginalização e reduzir as desigualdades sociais e regionais; IV - promover o bem de todos, sem preconceitos de origem, raça, sexo, cor, idade e quaisquer outras formas de discriminação. Art. 5‥ Todos são iguais perante a lei, sem distinção de qualquer natureza, garantindo-se aos brasileiros e aos estrangeiros residentes no País a inviolabilidade do direito à vida, à liberdade, à igualdade, à segurança e à propriedade, (...).
} 
capacidade de conduzir o próprio veículo e dependem de terceiros para conduzi-lo - Deficiência destes que se mostra de grau ainda maior Observância dos princípios constitucionais da igualdade, dignidade da pessoa humana e isonomia tributária - Inteligência dos artigos 10 e 50, "caput", da Constituição Federal - Prova suficiente da condição de pessoa especial e da negativa do benefício pleiteado - Direito líquido e certo do impetrante - Reexame necessário não provido.

Destaca-se ainda, como uma solução é ampliar o texto para que o deferimento seja para toda e qualquer deficiência ou doença incapacitante que gera de certa forma alguma deficiência, haja vista que tornará efetivo não só o princípio da segurança jurídica, mas também o princípio da isonomia tributária, de forma a tratar de forma igual os iguais e de forma desiguais os desiguais na medida de sua desigualdade, conforme o posicionamento abaixo:

Tendo em vista as várias isenções subjetivas que ofendiam o princípio da isonomia em seu duplo aspecto retro examinado, o constituinte de 1988 prescreveu o aludido princípio de forma bem enfática como se pode depreender do seu artigo 150, II: “Art. 150. Sem prejuízo de outras garantias asseguradas ao contribuinte, é vedado à União, aos Estados, ao Distrito Federal e aos Municípios:...II - instituir tratamento desigual entre contribuintes que se encontrem em situação equivalente, proibida qualquer distinção em razão de ocupação profissional ou função por eles exercida, independentemente da denominação jurídica dos rendimentos, títulos ou direitos;". A redação detalhada do texto retro transcrito impede seja contornado o princípio da isonomia por meio de rótulos dados aos rendimentos, títulos ou direitos, bem como veda expressamente a distinção em razão da ocupação profissional ou função exercida pelo contribuinte. (HARADA, Kiyoshi)

Portanto, fica evidente que deve prevalecer a proteção constitucional e dos princípios que a norteiam para possibilitar a isenção do IPVA para aqueles deficientes impossibilitados de dirigir veículo automotor, mas que tem terceiros, que se dedicam de forma integral a eles, não havendo justificativa para qualquer indeferimento, garantindo assim, além do 'princípio da isonomia, também da segurança jurídica.

\section{CONCLUSÃO}

O estudo do princípio da segurança jurídica pode ser direcionado para diversos ramos do direito, principalmente no direito tributário, quando diante o indeferimento por via administrativa da isenção do IPVA na aquisição de veículo automotor, para pessoas com deficiências e impossibilitadas de ser condutoras do automóvel adquirido, que mesmo com a modificação do texto legal, não trouxe em seu corpo legal de forma expressa se é toda e qualquer deficiência ou alguma específico, deixando a carga de normas regulamentares.

Portanto, em atenção à Constituição Federal, é nítido que também o deficiente não habilitado para dirigir deve ter referida isenção. Ora se ao portador de deficiência física a isenção há dos impostos federais (IPI) e estaduais (ICMS) para aquisição de veículos, torna-se uma afronta ao princípio da segurança jurídica o indeferimento nos casos de isenção para o IPVA - imposto sobre a propriedade de veículo automotor.

Assim, é de rigor nos casos de indeferimento deste imposto a propositura de mandado de segurança, garantindo mais um direito a pessoa com deficiência, e respeito ao princípio da isonomia e principalmente a concretização do princípio da segurança jurídica. 


\section{REFERÊNCIAS}

ÁVILA, Humberto. Segurança Jurídica - entre a permanência, mudança e realização no Direito Tributário. São Paulo: Editora Malheiros, 2011.

BRASIL. Supremo Tribunal Federal. ADI 2076. Relator: Min. Carlos Veloso: Partido Social Liberal - PSL. Requerido: Assembleia Legislativa do Estado do Acre. Brasília, 15 ago. 2002. Disponível em: $<$ http://redir.stf.jus.br/paginadorpub/paginador.jsp?docTP=AC\&doclD=375324>. Acesso em: 23 abr. 2017.

BRASIL. Lei no 13.296/2008, modificada pela lei no 16.498/2017. Disponível em: « http://www.al.sp.gov.br/repositorio/legislacao/lei/2008/alteracao-lei-13296-23.12.2008.html»>. Acesso em 23 set. 2017.

BRASIL. Tribunal de Justiça do Estado de São Paulo. Disponível em: << https://tjsp.jusbrasil.com.br/jurisprudencia/474844808/apelacao-apl-10017415520178260554-sp1001741-5520178260554/inteiro-teor-474844878 >>. Acesso em 23 set. 2017.

HARADA, Kiyoshi. Isenções e o Princípio da isonomia Tributária. Disponível em: $<$ http://www.ambito-juridico.com.br/site/?n_link=revista_artigos leitura\&artigo id=11595>>.

Acesso em 23 de set. 2017.

NASCIMENTO, Carlos Valder. THEODORO JUNIOR, Humberto. FARIA, Juliana Cordeiro. Coisa Julgada Inconstitucional - "A questão da segurança jurídica". Belo Horizonte: Editora Fórum, 2011.

SILVA, Otto Marques da. A História da Pessoa Deficiente no Mundo de Ontem e de Hoje. Epopéia Ignorada , 1987

THEODORO JUNIOR, Humberto. "As reformas do Direito Processual Civil e o Princípio Constitucional da Segurança Jurídica". In: MARTINS, Ives Granda da Silva; JOBIM, Eduardo. (Coord.). O processo na Constituição. São Paulo: Editora Quartier Latin do Brasil, 2008. 